\title{
ELISA LUCINDA ENTRE O VERBAL E O NÃO VERBAL: AFIRMAÇÃO E RESISTÊNCIA DE UMA MULHER NEGRA
}

\author{
ELISA LUCINDA ENTRE EL VERBAL EL NO VERBAL: AFIRMACIÓN Y \\ RESISTENCIA DE UNA MUJER NEGRA
}

ELISA LUCINDA BETWEEN VERBAL AND NON-VERBAL: AFFIRMATION AND RESISTANCE OF A BLACK WOMAN

\author{
Dayane Soares Magalhães \\ Universidade do Estado da Bahia \\ Elizeu Pinheiro da Cruz \\ Universidade do Estado da Bahia \\ Sidnay Fernandes dos Santos \\ Universidade do Estado da Bahia \\ Maria Angélica Rosa Fagundes Laranjeira Lessa \\ Universidade do Estado da Bahia
}

\section{RESUMO}

Neste texto, busca-se entender como Elisa Lucinda mobiliza o verbal e o não verbal para fazer circular discursos que materializam sentidos de afirmação e resistência que se inscrevem numa coletividade de mulheres negras. Para tanto, utiliza-se os mecanismos da Análise do Discurso. Definiu-se como fonte analítica que permitiu os contornos deste texto um vídeo no qual Lucinda recita o poema Mulata Exportação, da sua autoria. Foi possível compreender que o poema e as imagens em vídeo estabelecem regularidade e compõem as condições de produção de seus discursos de militância. Os elementos verbais (escrita e oralidade) e elementos não verbais (tons de voz e imagens cênicas) da enunciadora apresentam, no escopo da materialidade analisada, marcas das vivências que produzem as suas condições de existência como mulher negra.

Palavras chave: Elisa Lucinda. Discurso. Resistência.

\section{RESUMEN}

En este texto, se busca entender cómo Elisa Lucinda moviliza el verbal y el no verbal Lucinda para circular discursos que materializan significados de afirmación y resistencia inscritos en un grupo de mujeres negras. Se definió como fuente analítica que permitió los contornos de este texto un video en el cual Lucinda recita el poema Mulata Exportação, escrito por ella. Fue 
posible comprender que el poema y las imágenes en em video establecen regularidad y componen las condiciones de producción de sus discursos de activista. Los elementos verbales (escritos y hablados) y los elementos no verbales (tonos de voz e imágenes escénicas) de la enunciadora son, en el escopo del corpus analizado, fuertemente marcados por vivencias que producen sus condiciones de existencia como una mujer negra.

Palabras clave: Elisa Lucinda. Discurso. Resistencia.

\begin{abstract}
In this text, we seek to understand how the verbal and the non-verbal are mobilized by Elisa Lucinda to circulate speeches that materialize meanings of affirmation and resistance that are inscribed in a group of black women. An analytical source, that allowed the contours of this text, was defined, a video in which Lucinda recites her own poem named Mulata Exportação. It was possible to understand that the poem and the video images establish regularity and compose the conditions for the production of her activist speeches. The verbal elements (writing and orality) and non-verbal elements (tones of voice and scenic images) of the speaker are, within the scope of the analyzed corpus, strongly marked by experiences that produce their conditions of existence as a black woman.
\end{abstract}

Keywords: Elisa Lucinda. Discourse. Resistance.

\title{
1 Introdução
}

Elisa Lucinda demonstra forte preocupação com causas negra e feminina e, por meio dos seus posicionamentos, constrói sentidos que denunciam o racismo e o machismo. Nascida em Vitória no Espírito Santo, Elisa Lucinda cursou Comunicação Social pela Universidade Federal do Espirito Santo, formou-se em 1986, aos 28 anos. Naquele mesmo ano, foi para o Rio de Janeiro, almejando tornar-se atriz, e ingressou na Casa de Artes de Laranjeiras (CAL), onde cursou interpretação teatral. Fundou a Casa Poema, em 1998, na qual a ferramenta para o desenvolvimento da cidadania é a poesia falada. Atualmente, ela desenvolve os projetos (1) Palavra de Polícia, Outras Armas, cujas ações objetivam conscientizar policiais sobre os direitos humanos em relação a gênero e a raça; e (2) Versos de liberdade, em parceria com a Organização Internacional do Trabalho, no qual oferece aulas que trabalham a comunicação necessária para a vida e o mercado de trabalho com jovens, em instituições socioeducativas. A partir deste último trabalho, a ONU convidou Lucinda para desenvolver o projeto "Vidas Negras". A artista também recebeu prêmios e troféus como o troféu Raça Negra, na categoria teatro, em 2010, da ONG Afrobras em parceria com a Faculdade da Cidadania Zumbi dos 
Palmares e o Prêmio Altamente Recomendável, da Fundação Nacional do Livro Infantil e Juvenil (FNLIJ).

Elisa Lucinda é autora de 18 livros, entre eles: A Lua que menstrua (produção independente; 1992), Sósia dos sonhos (produção independente), O Semelhante (1995); Eu te amo e suas estreias (1999); A Menina Transparente (2000); 50 Poemas Escolhidos pelo Autor (2004); Contos de Vista (2005); A Fúria da Beleza (2006); A Poesia do encontro - em parceria com Rubem Alves - (2008); Parem de falar mal da rotina (2010); A Dona da Festa (2011); Fernando Pessoa, o Cavaleiro de Nada (2014); Vozes Guardadas (2016); Livro do avesso: o pensamento de Edite (2019). Para o livro Vozes Guardadas, sua professora do Curso de Interpretação Teatral de Poesia, Maria Filina Salles de Sá de Miranda, fez a apresentação e, em determinado momento, se expressou da seguinte forma:

Li estes versos e, mais uma vez, inebriei-me de sua poesia. Alma grandiosa,
alma que canta, que chora, que ri... Alma que fala dos sonhos de justiça para
o mundo, alma que fala dos sonhos acalentados pelo amor que está presente
no sono de todas as mulheres. Com ideias claras e distintas, com inspiração
permanente, seus versos falam também do cotidiano, das águas, dos jardins,
dos silêncios das cartas enviadas, mensagens que chegam ao nosso coração de
forma contundente. (MIRANDA apud LUCINDA, 2016, p. 13)

Como atriz, Elisa Lucinda participou de várias novelas, filmes e peças de teatro. Em 2018, esteve em cartaz o seu mais novo espetáculo: L, o Musical que, com um repertório de canções femininas, narra as relações de afeto entre seis mulheres.

Devido aos seus trabalhos, Elisa Lucinda é convidada para dar entrevistas, escrever e proferir palestras que tematizam as questões de gênero e etnia na sociedade brasileira. Uma das provocações que ela apresenta nas palestras é: "você é um abolicionista moderno ou um escravagista?". Com esse tema/questionamento, ela expõe várias situações cotidianas que perpetuam na vida das negras e dos negros, na maioria das vezes, de maneira mascarada. Em suas palestras e textos escritos, ela trata da dificuldade para uma mulher negra conseguir um papel de destaque em novelas e filmes. Lucinda afirma que o apartheid é uma prática comum no Brasil, visto que este ocorre quando há divisões de território, conforme explica em entrevista do Programa Roda Vida em 2017i: "Se tem território, tem apartheid. Eu sei onde ir e encontrar só brancos e ir em outros e encontrar só negros". Todas essas abordagens de Lucinda parecem estar em consonância com aquilo Donna Haraway (2009) denomina objetividade feminista ${ }^{\mathrm{ii}}$. Assim, Elisa Lucinda está situada na posição socioideológica de mulher negra que é contra o 
racismo e o machismo, aparecendo entre o verbal e não verbal como responsável pelo que aprendeu a ver.

Além disso, em suas múltiplas formas de dizer e escrever aquilo que considera necessário, a partir da sua vivência cotidiana enquanto mulher negra, há uma dimensão de "escrevivência" no trabalho de Lucinda, aquilo que Conceição Evaristo definiu, em uma entrevista de 2016 $6^{\mathrm{iii}}$, como uma escrita marcada pela condição de mulher negra: "Eu sempre tenho dito que a minha condição de mulher negra marca a minha escrita, de forma consciente inclusive. Faço opção por esses temas, por escrever dessa forma. Isso me marca como cidadã e me marca como escritora também".

Elisa Lucinda, a partir da sua vivência de mulher negra também expressa essa condição por meio de seus dizeres, como ela mesma afirma, em entrevista ao Roda Viva: “eu me lembro que tem um programa que eu faço no Canal Brasil com o Erlanger e o José Junior. E o Erlanger diz assim: 'Elisa, todo programa você põe o assunto de racismo'. Mas não sou eu que ponho, ele está em todos os lugares". Lucinda, reiteradamente, exemplifica seus posicionamentos com histórias vividas por ela em situações diversas.

Diante dessas informações que caracterizam Elisa Lucinda como mulher e negra ou, dito de outra forma, caracterizam-na como sujeito empírico, elegemos um poema para analisar os posicionamentos do sujeito discursivo na perspectiva de interpretar, na materialidade linguageira, a relação que se estabelece entre a mulher negra e militante e o sujeito discursivo que enuncia em uma dada conjuntura sócio-histórica. Nesse sentido, questionamos: como os elementos verbais e não verbais se complementam para construção de um sujeito discursivo que se posiciona como militante?

A curiosidade que move este trabalho encontra justificava na importância de Lucinda enquanto intelectual e artista negra engajada em questões sociais das mulheres negras e outras minorias.

\section{A enunciação no palco: conceitos discursivos em cena}

Valendo-se de conceitos saussurianos acerca da linguagem, Vera Aguiar (2004) pondera que a linguagem não verbal é constituída por significante e significado. Para ela, música, pintura, cinema, moda, cozinha e tantas outras linguagens não verbais se valem também de signos que se compõem dos significantes, como movimento, som e cor, e dos significados, 


\section{ELISA LUCINDA ENTRE O VERBAL E O NÃO VERBAL: AFIRMAÇÃO E RESISTÊNCIA DE UMA MULHER NEGRA}

como os conceitos. Significantes da linguagem corporal são utilizados pela enunciadora Elisa Lucinda, tanto de forma verbal, quando se trata de seus discursos militantes, da sua literatura, dos seus personagens; quanto de forma não verbal, quando se trata da imagem atribuída a ela como mulher negra, que detém um lugar de fala de destaque por estar presente na mídia (televisão, internet etc.), na literatura e ser ativista no movimento negro. Além disso, sua imagem visual, no que se refere à cor da sua pele, ao seu cabelo, a sua vestimenta, aos acessórios que usa (como turbante e colares), ao seu gênero, aos movimentos feitos e à entonação de sua voz ao discursar ou ao declamar um poema, também contam como linguagem não verbal.

Como aporte teórico-metodológico, mobilizamos os conceitos de entonação valorativa de Dahlet (2005) e enunciação de Brait e Melo (2008), ambos na perspectiva bakhtiniana; escrevivência de Evaristo (2016), performance de Zumthor (2005) e papel de Maingueneau (2004). A partir destes, foi analisada a apresentação de Elisa Lucinda em um vídeo no qual declama o seu poema Mulata Exportação.

Papel, de acordo com Maingueneau (2004), é uma determinação que seguimos dentro da sociedade, a forma como agimos baseado em quem nós somos. Essa ideia vem da Antiguidade, de "uma longa tradição de moralistas que consideram as interações sociais como um imenso teatro no qual tudo o que se faz é representar papéis. Depreende-se dessa formulação que as personalidades são moldadas pelos papéis em que atuam (MAINGUENEAU, 2004, p. 69).

Outras noções importantes são "enunciado" e "enunciação", elas têm papel centralizador na concepção de linguagem, visto que esta é realizada através do histórico, social e cultural, inclui o ato efetivo de comunicação, discursos e sujeitos envolvidos (BRAIT; MELO, 2008).

$\mathrm{Na}$ enunciação, elementos verbais e não verbais podem estar articulados em um dado contexto histórico. Conforme Voloshinov (1926), a situação externa ao verbal não é simplesmente a causa do enunciado, ela é parte necessária na constituição do significado. Todo enunciado concreto significativo é composto por duas partes, uma é a observada em palavras e a outra é a presumida pelo contexto. Se houver um interlocutor que não conhece o contexto, o enunciado perde quase todo o sentido para ele. Por isso, na perspectiva bakhtiniana, as concepções de enunciado e, principalmente, de enunciação são necessárias neste movimento de buscar respostas para o questionamento presente neste estudo. 
Outro conceito que serviu de apoio foi o conceito de "entonação", que se refere ao tom em que o enunciado é dito, pois, a partir da escolha da entonação, significados diferentes são atribuídos ao enunciado. A entonação é um aspecto extralinguístico importante que deve ser levado em conta na análise da enunciação. Segundo Véronique Dahlet (2006, p. 251), “[...] a entonação é lugar de memória e lugar de encontro". Para ela, autor e leitor, desde a infância, estão impregnados de entonação e, por isto, ela é memoria acústica e social. Ou seja, podemos inferir, a partir desta formulação, que Elisa Lucinda, alvo desta análise, e os seus leitores, fazem aparecer as suas entonações como lugar de encontro das suas entonações respectivas.

Dahlet (2006, p. 255) aponta ainda a consideração de Bakhtin de que o texto tem a capacidade de solicitar, mobilizar, impulsionar e agir sobre o corpo, por meio do que chama de “interiorização do material verbal". Ou seja, o corpo estabelece uma relação com o texto verbal, sobretudo no texto poético, ele segue os direcionamentos dados pelo texto verbal.

No vídeo em que Lucinda declama seu poema Mulata Exportação, é verificável a representação cênica do papel de uma mulher negra que teve seu corpo objetificado pelo sujeito que ela denomina de ex-feitor. E, para expressar as ações do ex-feitor e os sentimentos diante dessa objetificação, a enunciadora utiliza a entonação expressiva. E, segundo Zumthor (2005, p. 70), a diferença entre o texto escrito e a performace dele é que "esta viabiliza uma presença tátil, uma situação de diálogo que se estabelece entre a palavra, a percepção que temos dela e os efeitos psíquicos gerados em nós".

\section{3 "Mulata exportação": produção de sentidos pelo verbal e não verbal}

O texto selecionado para análise é um vídeo disponível no YouTube $e^{\mathrm{iv}}$. Nele, a enunciadora Elisa Lucinda declama o poema Mulata Exportação de sua autoria, conforme já dissemos. Interessou-nos os efeitos do discurso verbal e do não verbal dele decorrentes a fim de compreender como ambos dialogam e estabelecem consonância.

Logo no início do poema, o sujeito discursivo, para se referir à mulher negra, utiliza um termo pejorativo, nega, que evoca de forma ideologicamente negativa à historicidade do negro; o sujeito utiliza vocativos que denotam a mulher como um objeto sexual de sua posse; entre estes, utiliza o "nega exportação" como se ela fosse um produto de mercado, como já foi considerada no período escravocrata, vindo de outro país para satisfazer os clientes. Assim, há 


\section{ELISA LUCINDA ENTRE O VERBAL E O NÃO VERBAL: AFIRMAÇÃO E}

RESISTÊNCIA DE UMA MULHER NEGRA

uma relação com o passado. Ademais, ainda existe, e se constata na voz do poema, uma fantasia sexual em relação ao corpo negro como objeto de prazer fácil e garantido.

$\mathrm{Na}$ declamação, Lucinda dispõe de uma ferramenta importantíssima para a valorização do poema: a entonação expressiva que o colore. Essa entonação já existe na escrita, mas, ao estabelecer uma ligação entre corpo e voz no funcionamento da entonação, esta passa a mobilizar o corpo, inclusive o aparelho fonador, fazendo com que se concretize na enunciação. Através dessa entonação, ela consegue expressar a euforia do ex-feitor, o desejo imediato e incontrolável e a falta de respeito com mulher negra. Além disso, dispõe também de uma linguagem corporal que representa o sentimento do sujeito discursivo em cada momento de fala:

1. Mas que nega linda

2. E de olho verde ainda

3. Olho de veneno e açúcar!

4. Vem nega, vem ser minha desculpa

5. Vem que aqui dentro ainda te cabe

6. Vem ser meu álibi, minha bela conduta

7. Vem, nega exportação, vem meu pão de açúcar!

(LUCINDA, 1997, pp. 184-185)

Aqui, no geral, prevalece um tom de desejo e persuasão, nos três primeiros versos, ela faz uso de um tom de admiração. No fragmento acima, é possível perceber um aspecto polifônico, isto é o fragmento representa as vozes que a sociedade vem construindo de que "em geral os negros não são bonitos, e que se deve admirar quando são”, como espanto. Além disso, no sétimo verso, quando ela declama no vídeo, "vem meu pão de açúcar", a enunciadora faz uma representação corporal e entoada como se estivesse mesmo "derretendo" de desejo no intuito de dar mais significação à palavra açúcar.

8. Monto casa procê mas ninguém pode saber, entendeu meu dendê?)

9. Minha tonteira, minha história contundida

10. Minha memória confundida, meu futebol, entendeu meu gelol?

11. Rebola bem meu bem-querer, sou seu improviso, seu karaoquê;

12. Vem nega, sem eu ter que fazer nada.

13. Vem sem ter que me mexer

14. Em mim tu esqueces tarefas, favelas, senzalas, nada mais vai doer.

15. Sinto cheiro docê, meu maculelê, vem nega, me ama, me colore

16. Vem ser meu folclore, vem ser minha tese sobre nego malê.

17. Vem, nega, vem me arrasar, depois te levo pra gente sambar.

(LUCINDA, 1997, p. 184-185) 


\section{ELISA LUCINDA ENTRE O VERBAL E O NÃO VERBAL: AFIRMAÇÃO E}

RESISTÊNCIA DE UMA MULHER NEGRA

Considerando a oralidade (declamação gravada em vídeo), o oitavo verso é expresso em tom de segredo, baixo. Esse elemento linguageiro, tal como usado, reforça o sentido de como o negro e as mulheres, independentemente de cor, ainda são vistas como mercadorias e suscetíveis de compra, de escambo, de tráfico. Compreende-se por esses versos também, como linguagem o silenciamento imposto pelo ex-feitor. Conforme Eni Orlandi (2007, p. 72-75), a política do silêncio "produz um recorte entre o que se diz e o que não se diz" e, dentro da concepção de política do silêncio, existe o silêncio local que é a forma mais visível pela qual a interdição do dizer se manifesta.

O ex-feitor sabe da situação na qual a negra está inserida e faz uso disso para convencêla de que será bom fazer o que lhe propõe, oferece-lhe casa, argumentando ser "seu improviso", "seu Karaokê". Evoca substantivos que trazem junto a si uma historicidade profunda e perpetuadora, "Em mim tu esqueces tarefas, favelas, senzalas, nada mais vai doer", referindose ao período da escravidão e pós-abolição, no qual negras e negros tornaram-se livres, mas sem acessar as mesmas condições de mulheres e homens brancos.

Mas antes a chama de "minha história contundida", percebe-se neste enunciado o prazer de estar se apossando de alguém que muito sofreu. Ou seja, é um sujeito homem consciente da história de negras e negros, das suas dores e dos seus sofrimentos, e usa isso para se promover como a "esperança de salvação" da situação em que se encontra sua interlocutora.

Nos versos nove e dez, a enunciadora declama com entonação que sugere a representação dos gemidos de prazer do ex-feitor ao imaginá-los juntos. Depois, continua com o tom de desejo, com vocativos metafóricos e emprega palavras africanas ditas no Brasil, como procê, dendê, docê, maculelê. O sujeito ex-feitor usa essas palavras como uma forma de aproximação da linguagem da interlocutora, como da mesma forma infantilizada que se conversa com crianças, o que faz pensar que é necessário utilizar de palavras mais próximas ao vocabulário da mulher negra, como se ela fosse incapaz de entender a sua, como se ela fosse estúpida ou retardada.

Nos versos doze e treze, ao declamá-los, a artista Elisa Lucinda mais uma vez representa corporalmente o que diz com uma requebrada na cintura para ilustrar o verbal: "Vem nega, sem eu ter que fazer nada, vem sem ter que me mexer". É o corpo compondo com as instruções do texto verbal, é a interiorização desse ato verbal. Mesmo que a fala seja de negação do movimento, o sujeito discursivo (o ex-feitor) se movimenta ilustrando o que ele não precisaria fazer. E, no verbal, mais uma vez, a mulher negra é tratada de forma idealizada no que se refere 


\section{ELISA LUCINDA ENTRE O VERBAL E O NÃO VERBAL: AFIRMAÇÃO E RESISTÊNCIA DE UMA MULHER NEGRA}

ao sexo, um objeto de prazer garantido, visto que se imagina ser desnecessário fazer algo, que ela sozinha comandaria a relação sexual.

No verso dezesseis, "vem ser meu folclore, vem ser minha tese sobre nego malê", a mulher negra é colocada como objeto de estudo que, possivelmente, renderia uma tese. Esse sentido de estudo exprime uma curiosidade em relação à mulher negra que não é encarada como qualquer outra, mas como um ser idealizado sexualmente, um ser exótico que precisa ser estudado. Além disso, percebe-se um ar de deboche quando ela relata a metáfora usada pelo exfeitor de ser até seu "folclore", a enunciadora altera a voz como quem não acredita no que ouviu.

Já é possível perceber uma mudança na entonação da voz no verso dezessete que é o último verso de fala do ex-feitor. Nesse verso, ela declama com um tom de desagrado trazendo, na voz, a vítima que conta o que ouviu. Então, a entonação na fala do ex-feitor foi muito necessária, e mais importante é a mudança de entonação, que demonstra quem é o sujeito da fala. Esta mostra que, na verdade, não é ele, mas é ela. Assim, o interlocutor percebe que se trata de um protesto do sujeito que tem o lugar de fala e se apropria deste para denunciar as mazelas sociais sofridas pela mulher negra.

Nessas sequências discursivas está o cerne da análise: o lugar de fala de Elisa Lucinda, o que a imagem dela representa em seus discursos verbais.

18. Imaginem: Ouvi tudo isso com calma e sem dor.

(LUCINDA, 1997, p. 184-185)

No verso acima, ocorre uma ironia, o que, segundo os estudos de Castro (1997), Bakhtin denomina discurso bivocal, o texto irônico, através do processo enunciativo, dizer algo, mas também dizer algo contra a própria enunciação. Ou seja, ao mesmo tempo em que se diz algo, se nega, Elisa Lucinda faz isso no verso dezoito. Afirma ter ouvido "tudo isso com calma e sem dor" quando na verdade provoca um efeito de sentido contrário. De acordo com os estudos bakhtinianos, na ironia, a palavra tem duplo sentido, um que seria o comum, o que realmente está escrito e outro que significa o contrário do primeiro, e o reconhecimento do segundo contexto é o meio de perceber o significado da ironia. Percebemos que a ironia é um elemento muito presente na linguagem da enunciadora.

Nos versos que seguem, expressa também, com voz inconformada, as dores e as injustiças praticadas por uma sociedade machista e racista, quando se dirige ao juiz e ao delegado fazendo uso de uma voz que pede socorro e que se irrita pela passividade diante de

\begin{tabular}{l|l} 
Revista RBBA & Revista Binacional Brasil Argentina
\end{tabular} 
tamanho abuso. Faz, ainda, uma crítica à lei que, além de decretar pequena pena, assegura cela especial para quem possui ensino superior. A insinuação do juiz e o piscar do delegado mostram que a mulher, sobretudo a mulher negra, não é ouvida na sociedade, e que os homens se apoiam, em função do gênero, da cor e da classe social-econômica.

19. Já preso esse ex-feitor, eu disse: "Seu delegado..."

20. E o delegado piscou.

21. Falei com o juiz, o juiz se insinuou e decretou pequena pena

22. com cela especial por ser um cara intelectual...

23. Eu disse: "Seu Juiz, não adianta! Opressão, Barbaridade, Genocídio

24. nada disso se cura trepando com uma escura!"

25. Ó minha máxima lei, deixai de asneira

26. Não vai ser um branco mal resolvido

27. que vai libertar uma negra

28. Esse está fadado

29. porque não é com lábia de pseudo-oprimido

30. que vai aliviar seu passado.

(LUCINDA, 1997, p. 184-185)

Há, na interpretação oral desses versos, uma encenação corporal maior quando ela simula uma corrida até o delegado e mobiliza um tom vocativo para chama-lo. Bem como, quando fala que o delegado piscou, representa uma indignação acompanhada de surpresa, através do tom de sua voz e do gesto com a mão. Além disso, a indignação fica estampada em sua face. Isso ocorre também quando o sujeito enunciador fala ao juiz que é a voz da corrupção, quando ela conta a resposta do juiz, levanta a mão e balança como quem cita um discurso repetitivo. Mas, quando ela responde ao juiz, o movimento de sua mão muda e imediatamente é incorporada uma força no braço que é erguido pela indignação que também é percebida na voz alterada, expressando força, pela vontade de fazê-lo entender que mudanças precisam ocorrer. Durante esse discurso, quando ela diz "nada disso se cura trepando com uma escura", ao dizer "escura", ela simula o uso de aspas, provavelmente porque escura não é o termo adequado a se usar do que negra. Assim esclarece que o termo escura é pejorativo e não parte de si/enunciadora mulher, mas dos discursos equivocados e preconceituosos de outras pessoas.

Essa parte é marcada, sobretudo, por uma autoafirmação, que mostra sua potencialidade enquanto mulher negra conhecedora das injustiças praticadas, que levanta a voz para se impor, para falar, mesmo que não seja ouvida. 
RESISTÊNCIA DE UMA MULHER NEGRA

31. Olha aqui meu senhor:

32. Eu me lembro da senzala

33. e tu te lembras da Casa-Grande

34. e vamos juntos escrever sinceramente outra história

35. Digo, repito e não minto:

36. Vamos passar essa verdade a limpo

37. porque não é dançando samba

38. que eu te redimo ou te acredito:

(LUCINDA, 1997, p. 184-185)

Nesses primeiros versos, há referência ao período histórico escravagista, metaforizado pelos termos senzala e casa grande que representam a hierarquia, o sofrimento e as desigualdades da época, mas que ainda refletem nos dias atuais. Depois de evocar essa historicidade, faz um apelo para a construção de uma nova história, ao mesmo tempo em que o verbal, a corporeidade e voz trazem muita significação. Estas marcam um conhecimento compartilhado que exige honestidade de ambas as partes em relação ao que esse conhecimento representa.

39. Vê se te afasta, não invista, não insista

40. Meu nojo!

41. Meu engodo cultural!

42. Minha lavagem de lata!

43. Porque deixar de ser racista, meu amor,

44. não é comer uma mulata!

(LUCINDA, 1997, pp. 184-185)

Ocorre, nesse final, uma inversão da situação. Se, no início, o ex-feitor tentava convencê-la de ser sua com vocativos de cunho sexual, nesses versos a enunciadora ordena que ele (sujeito ex-feitor como interlocutor) se afaste e o chama, com entonação de nojo e de raiva, de nomes pelos quais ela o vê representado mediante sua conduta em relação a ela, sua história e sua cultura. E finaliza dizendo que deixar de ser racista não é "comer" uma mulata.

\section{Considerações finais}

A partir deste estudo, foi possível entender que o verbal e o não verbal são mobilizados por Elisa Lucinda para fazer circular discursos que materializam sentidos de afirmação e resistência que se inscrevem numa coletividade de mulheres negras através da união de sua 
expressividade corporal, com movimentos e entonação expressiva, e seus saberes situados no que se refere à história das negras e dos negros brasileiros.

Há também a percepção de que Elisa Lucinda seja um exemplo de que Jamais fomos modernos, formulação de Latour (1994), pois não busca separar suas ações umas das outras, nem o momento, não deixa de abordar sobre racismo ou machismo quando o assunto é teatro, nem deixa de ser atriz quando o assunto é racismo e machismo. Nas palavras dela, "essas são ações que eu chamo de ações dentro da vida, é preciso que a gente aja dentro da vida, com cenas. O Boal pregava isso, esse teatro invisível ${ }^{\mathrm{v}}$, ele é muito revolucionário, e está na nossa mão" (Aula inaugural- SP Teatro) ${ }^{\mathrm{vi}}$.

\section{REFERÊNCIAS}

AGUIAR, Vera Teixeira de. O verbal e o não verbal. São Paulo: UNESP, 2004.

BRAIT, Beth; MELO, Rosineide de. Ideologia. In.: BRAIT, B. (Org.). Bakhtin: conceitoschave. 4. ed. São Paulo: Contexto, 2008.

CASTRO, Maria Lília Dias de. A dialogia e os efeitos de sentido irônicos. In.:BRAIT, Beth. Bakhtin, dialogismo e construção do sentido, 2. ed. Campinas, São Paulo: Editora da Unicamp, 1997.

CAZES, Leonardo. Conceição Evaristo: a literatura como arte da "escrevivência". O Globo, 11 jul. 2016. Disponível em: https://oglobo.globo.com/cultura/livros/conceicao-evaristoliteratura-como-arte-da-escrevivencia-19682928. Acesso em: 28 set. 2018.

DAHLET, Véronique. A entonação no dialogismo Bakhtiniano. In.: BRAIT, Beth. (Org.). Bakhtin, dialogismo e construção dos sentidos. 2. ed. Campinas, São Paulo: Editora da Unicamp, 2006.

ERZIJNI, Nádia. Amina Bin Qarrish de Tetuan: registros da vida de uma mulher marroquina do século XIX. Cad. Pagu, Campinas, n. 30, p. 43-52, jun. 2008. Disponível em: $<$ http://www.scielo.br/scielo.php?script=sci_arttext\&pid=S0104-

83332008000100005\&lng=pt\&nrm=iso>. Acesso em: 01 maio 2019.

HARAWAY, D. (2009). Saberes localizados: a questão da ciência para o feminismo e o privilégio da perspectiva parcial. Cadernos Pagu, (5), 7-41. Díisponível em: https://periodicos.sbu.unicamp.br/ojs/index.php/cadpagu/article/view/1773. Acesso em: 15 de junho de 2019.

LATOUR, Bruno. Jamais fomos modernos: ensaio de antropologia simétrica. Rio de Janeiro, RJ: Editora 34, 1994. 


\section{ELISA LUCINDA ENTRE O VERBAL E O NÃO VERBAL: AFIRMAÇÃO E RESISTÊNCIA DE UMA MULHER NEGRA}

LUCINDA, Elisa. Ser pobre não é defeito. Jornal do Brasil. Disponível em: http://www.jb.com.br/index.php?id=/acervo/materia.php\&cd_matia=918288\&dinamico=1\&p review=1. Acesso em: 26 set. 2018.

LUCINDA, Elisa. Vozes Guardadas. 1. ed. Rio de Janeiro: Record, 2016.

MAINGUENEAU, Dominique. Análise de textos de comunicação. São Paulo: Cortez, 2004.

ORLANDI, Eni Puccinelli. As formas do silêncio: no movimento dos sentidos. 6. ed. Campinas, São Paulo: Editora da Unicamp, 2007.

VOLOCHINOV, V; BAKHTIN. Discurso na Vida e Discurso na Arte: sobre a poética sociológica. Trad. de Carlos Alberto Faraco \& Cristóvão Tezza. Versão da Língua inglesa de I. R. TITUNIK a partir do original russo, 1926.

ZUMTHOR, Paul. Escritura e nomadismo: entrevistas e ensaios. Trad. Jerusa Pires Ferreira, Sonia Queiroz. - Cotia- SP: Ateliê Editorial, 2005.

\section{SOBRE OS AUTORES}

Dayane Soares Magalhães é Graduanda do curso de Letras, Língua Portuguesa e Literaturas da Universidade do Estado da Bahia, membro do grupo de pesquisa Ensino, Discurso e Sociedade (DisSE/UNEB/CNPq).

Endereço eletrônico: daianemagalhaessss @gmail.com ORCID: https://orcid.org/0000-0001-8342-9803

Elizeu Pinheiro da Cruz é Doutor em Ciências Sociais pela Universidade Federal da Bahia e Professor do Programa de Pós-Graduação em Ensino, Linguagem e Sociedade da Universidade do Estado da Bahia (UNEB de Caetité, Bahia). É líder do Grupo de Pesquisa Antropologia e Ambiente (UNEB/CNPq) e do Grupo Ensino, Linguagem e Sociedade (DisSE/UNEB/CNPq). Endereço eletrônico: elizeuprof@gmail.com

ORCID: https://orcid.org/0000-0003-1454-6832 
Sidnay Fernandes dos Santos é Doutora em Linguística pela Universidade Federal de São Carlos. Docente permanente no Programa de Pós-graduação em Ensino, Linguagem e Sociedade (PPGELS) da Universidade do Estado da Bahia, Caetité, Bahia, Brasil. Pesquisadora dos Grupos de Pesquisa Ensino, Discurso e Sociedade (DisSE/UNEB/CNPq) e do Laboratório de Estudos Epistemológicos e Discursividades Multimodais (LEED/IM/UFSCar/CNPq).

Endereço eletrônico: sidnayfernandes@ hotmail.com

ORCID: https://orcid.org/0000-0001-5932-4948

Maria Angélica Rosa Fagundes Laranjeira Lessa é Mestranda em Ensino, Discurso e Sociedade. Pós-graduada em Gestão Pública pela Universidade Aberta do Brasil UAB/UNEB e em Gestão Escolar pela Faculdade de Ciência, Tecnologia e Educação - FACITE. E graduada em Pedagogia pela Universidade do Estado da Bahia.

Endereço eletrônico: angfaglar@gmail.com

ORCID: https://orcid.org/0000-0002-6413-576X

Recebido em: 30/04/2020

Aprovado em: 02/06/2020

Publicado em: 01/07/2020

\section{Notas}

\footnotetext{
${ }^{i}$ Disponível em: https://www.youtube.com/watch?v=df5ujgc8be0. Acesso em: 05 de jul. de 2019.

ii Segundo a autora, "a objetividade feminista trata da localização limitada e do conhecimento localizado, não da transcendência e da divisão entre sujeito e objeto. Desse modo, podemos nos tornar responsáveis pelo que aprendemos a ver" (HARAWAY, 1995, p. 21).

iii Disponível em: <https://oglobo.globo.com/cultura/livros/conceicao-evaristo-literatura-como arte-daescrevivencia-19682928 > Acesso em: 10 de out. de 2018.

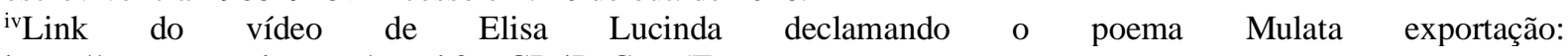
https://www.youtube.com/watch?v=GD4PoGwg5Ew

${ }^{v}$ Teatro Invisível acontece no espaço público em frente de espectadores que não sabem que são espectadores. $\mathrm{O}$ nome do teatrólogo brasileiro Augusto Boal (1931-2009), fundador do Teatro do Oprimido está ligado com este instrumento subversivo de intervenção política.

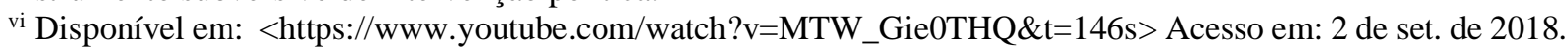

